\title{
Mucilage Wastes as a Source for Oils: Part II: Preparation of Nonionic Surfactants
}

\author{
M.G. Megahed", M.A. Abd El-Ghaffar*, A. Shahin ${ }^{* *}$ and \\ A.M. Rabie ${ }^{* * *}$ \\ Department of Fats and Oils, *Department of Polymers and \\ Pigments, National Research Center, Cairo, Egypt, ${ }^{* *}$ Corgal, \\ Algeria and ${ }^{* * *}$ Department of Chemistry, Faculty of Science, \\ Ain-Shams University, Cairo, Egypt.
}
7 WO NONIONIC surfactants named sunflower and cotton seed oil were prepared from sodium salt of sulphonated oils (Part I) by ethoxylation with ethylene oxide. The yield of nonionic surfactants obtained were $70 \%$ and $68 \%$, respectively.

The hydrophilic-lipophilic balance (HLB), surface tension, interfacial tension, microanalysis, wetting and foaming power were evaluated. Concerning the microanalysis of the prepared surfactants, the results are in a good agreement with theoretical values which confirm the proposed structures.

High performance surface activity properties were achieved. The importance of these eco-friendly products are due to an environmental and economical points of view.

The prepared surfactants showed more than $88 \%$ degradation after 21 days that can be considered agreat success for environment.

Keywords: Mucilage wastes, Sunflower oil, Cotton seed oil, Nonionic surfactants, Ethoxylation and Biodegradation

The application of sulphonated fatty acids is under development in various detergent products, but so far the realisation in products on the market is very restricted. $\mathrm{C}_{16}-\mathrm{C}_{18}$ fatty acids esters sulphonates show good surface activity, high detergent properties, dispersing and emulsifying power in hard water, high lime soap dispersion and moderate foam levels ${ }^{(1,2)}$. In the food industry, a foam cleaning process may be employed. Here, in addition to strongly foaming surfactants, foam stabilizers are utilized to achieve adhesion of the cleaning medium to the surface of the goods to be cleaned ${ }^{(3)}$.

These important applications of slufonated fatty acids are selected for preparation of nonionic surfactants by ethoxylation process ${ }^{(4)}$. The prepared nonionic surfactants were characterized for hydrophilic lipophilic balance (HLB), surface and interfacial tension, wetting and foaming powers, as well as, microanalysis of $\mathrm{C}, \mathrm{H}, \mathrm{S}$ and $\mathrm{N}$, in addition to evaluate their biodegradability.

${ }^{\#}$ Corresponding author, E-mail: dr_mgmegahed @ hotmail. com 
The literature is scantey concerning these types of prepared nonionic surfactants because they are based on some natural oils and fats extracted from mixture of waste materials (mucilage) .

The ultimate goal for this study is to prepare and evaluate new types of nonionic surfactants based on sulfonated oils extracted from waste materials (Mucilage).

\section{Materials}

\section{Materials and Methods}

Sulfonated sunflower and sulfonated cotton seed were prepared by sulfonation of their extract oils from mucilage (Part I).

\section{Methods}

Preparation of ethoxylated oils as nonionic surfactants

These surfactants were prepared according to the following steps:

Preparation of fatty acid sulphonyl chloride: This process was carried out according to the method reported by Marei and Badawi (5) with some modification as follow :

The sodium salts of fatty sulphonic acids were reacted with phosphorus penta-chloride (1:1.5 mole), respectively. The mixture was mixed well and refluxed to $90^{\circ} \mathrm{C}$ for $2 \mathrm{hr}$. After cooling, the reaction mixture was poured on crushed ice and the separated acid chloride was either filtered or extracted with ether. The acid chloride was then purified via crystallization by vacuum distillation.

Preparation of fatty acid sulphonamides: The oil sulphonyl chlorides were dissolved in ethanol and a stochiometric amount of ammonia liquor was added and the mixture solution was heated on a water bath for $30 \mathrm{~min}$. After cooling, the solution was then acidified, filtered and the obtained crude sulphonamides were dried and then crystallized from the suitable solvents.

Condensation of prepared fatty acid sulphonamides with ethylene oxide: This process was carried out according to the method reported by Sisido and Yagi ${ }^{(6)}$. The prepared fatty acid sulphonamides $(0.05$ mole $)$ and potassium hydroxide (0.002 mole) were placed in a previously weighed reaction vessel of the laboratory apparatus.

The mixture was then heated to $170-180^{\circ} \mathrm{C}$ and stirred under nitrogen atmosphere, flowing of nitrogen was stopped and passing the ethylene oxide was permitted with vigorous agitation of the mixture for $2 \mathrm{~min}$. After that, the flowing of ethylene oxide was regulated to a pressure of $10 \pm 0.5 \mathrm{~cm} / \mathrm{Hg}$, and the system was then closed. After a chosen interval of time, the introduction of ethylene oxide was stopped and the reaction was allowed to proceed until the pressure is dropped to zero. The apparatus was then filled with nitrogen, cooled and the reaction vessel weighed. The difference in weight showed the amount of

Egypt. J. Chem. 53, No. 4 (2010) 
ethylene oxide used in the reaction and its number of moles was calculated. The reaction mixture was then dissolved in ethyl alcohol, neutralized with hydrochloric acid and then filtered. After distillation of the ethyl alcohol, the product was obtained. The experiment was repeated for different intervals of time (1-7 hr).

Each of the prepared sulphonamide were again reacted with ethylene oxide as described previously, but for various reaction times suitable for condensation with certain number of moles of ethylene oxide ${ }^{(7)}$.

In each case the reaction time was determined. The minimum number of ethylene oxide units selected for each fatty acid sulphonamide adduct was dependent on the water solubility at room temperature of the prepared nonionic surfactants

\section{Evaluation of nonionic surfactants}

Microanalysis: The microanalysis of carbon ( C ), hydrogen ( $\mathrm{H}$ ) and sulfur ( S) were carried out using a Perkin Elmer 240B Microanalyzer ( USA ).

Hydrophilic - lipophilic balance ( $H L B$ ): Hydrophilic - lipophilic balance of nonionic surfactants was determined according to the method of Griffin ${ }^{(8)}$ using the following equation :

$$
\mathrm{HLB}=20(1-\mathrm{S} / \mathrm{A})
$$

where: S(Saponification value of nonionic surfactants) and A (acid value of total fatty acids of the original sample after hydrolysis of triglyceride fraction)

Surface and interfacial tension: Surface and interfacial tension of nonionic surfactants in xylene at $25^{\circ} \mathrm{C}$ were measured as previously reported by Alexander and Hayter ${ }^{(9)}$ using CSC - DuNouy Interfacial Tensiometer Model 70545 (CSC Scientific Company, Fair fax, Va) .

Wetting power: Wetting power of prepared surfactants was determined according to the method of Schigfner ${ }^{(10)}$ based on immersing a skein of standard textile sample with fixed concentration, temperature, hardness of water and period of aging.

Foaming power: Foaming power of prepared nonionic surfactants were determined according to the method of Ross and Miles ${ }^{(11)}$. Various parameters must be established during the test, such as concentration of surfactant, water hardness, temperature of solution and period of aging.

Biodegradability of nonionic surfactants: Two biological test methods (OECD screening test and OECD confirmatory test) are mandated for establishing biodegradability according to Organization for Economic Cooperation and Development (OECD) ${ }^{(12)}$. 
I) OECD screening test

The OECD screening test is preliminary test for exploring the biodegradability of detergents. In this producer, a mineral salt solution is incubated of MBAS (Methylene blue active substance) or BiAS (Bismuth active substance) as the role source of carbon. The MBAS or BiAS loss is determined at fixed intervals for up to 19 days, and the results are compared to the behavior of two control substances:

The poorly degradable TPS (tetra propylene benzene sulfonate) $(<35 \%$ loss) and the readily degradable LAS (linear alkyl benzene sulfonate) (92\% loss).

\section{II) OECD confirmatory test}

The OECD confirmatory test is a continuous procedure more closely relate to practice. It simulates through a prescribed test procedure the biodegradation that occurs in an activated sludge. These methods are reported by Vorodnung and Reinigung smitteln (1980) (13).

\section{Results and Discussion}

\section{Preparation of non-ionic surfactants}

Nonionic surfactants were prepared according to the following steps:

1. Reaction of the soldium salt of sulphonated fatty acids with phosphorus pentachloride leading to the formation of fatty acid sulfonyl chloride as illustrated in the following scheme:

$$
\text { F.A-SO } 3 \mathrm{Na}+\mathrm{PCl}_{5} \frac{90^{\circ} \mathrm{C}}{2 \text { hours }}-\mathrm{F} \cdot \mathrm{A}-\mathrm{SO}_{2} \mathrm{Cl}
$$

(Soidum salt of fatty sulphonic acid)

(Fatty acid sulphonyl chloride)

The fatty acid sulphonyl chlorides were confirmed by microanalysis for the formation of sulphonyl moiety in the chain and the data are given in Table 1.

TABLE 1. The yield and microanalysis of the prepared fatty acids sulphonyl chloride.

\begin{tabular}{|c|c|c|c|c|c|c|c|c|c|}
\hline \multirow{2}{*}{$\begin{array}{c}\text { Fatty acid } \\
\text { sulphonyl } \\
\text { chloride }\end{array}$} & \multirow{2}{*}{$\begin{array}{c}\text { Yield } \\
(\%)\end{array}$} & \multicolumn{2}{|c|}{ C\% } & \multicolumn{2}{|c|}{ H\% } & \multicolumn{2}{c|}{ S\% } & \multicolumn{2}{c|}{ Cl\% } \\
\cline { 3 - 10 } & & Theo. $^{*}$ & Fd. $^{* *}$ & Theo. & Fd. & Theo. & Fd. & Thei. & Fd. \\
\hline Sunflower & 70.0 & undefined & 14.95 & undefined & 2.57 & undefined & 11.05 & undefined & 9.67 \\
\hline Cotton seed & 63.0 & undefined & 15.46 & undefined & 2.66 & undefined & 11.73 & undefined & 10.27 \\
\hline
\end{tabular}

${ }^{*}$ Theo. $=$ Theoretical $\quad{ }^{* *}$ Fd. $=$ Found

It can be seen from Table 1 that the found microanalysis data of Sulpher and Chlorine of both sunflower and cotton seed fatty acid sulphonyl chloride confirm the formation of the proposed sulphonyl chloride fatty acid structures.

Egypt. J. Chem. 53, No. 4 (2010) 
From the obtained results it could be also noticed that sunflower fatty acids sulphonyl chloride had higher yield (70\%) compared with cotton seed fatty acids $(63 \%)$.

2.Reaction of the fatty acid sulphonyl chloride solution in alcohol with ammonia for $30 \mathrm{~min}$. forming fatty acid sulphonamide as reported by Englert et. al., ${ }^{(14)}$.$$
\text { F.A-SO }{ }_{2} \mathrm{Cl}+\mathrm{NH}_{3} \frac{\text { Ethyl alc. }}{\text { heat } 30 \text { mins }} \quad \text { F.A }-\mathrm{SO}_{2} \mathrm{NH}_{2}
$$ \\ (Fatty acid sulphonyl chloride)}

(Fatty acid sulphonamide)

They fatty acids sulphonamide were confirmed by microanalysis of ( $\mathrm{S}$, and N) and the data are given in Table 2.

TABLE 2. The yield and microanalysis of the prepared fatty acid sulphonamide .

\begin{tabular}{|l|c|c|c|c|c|c|c|c|c|}
\hline \multirow{2}{*}{$\begin{array}{c}\text { Fatty acid } \\
\text { sulpho- } \\
\text { namide }\end{array}$} & $\begin{array}{c}\text { Yield } \\
(\%)\end{array}$ & \multicolumn{2}{|c|}{ C\% } & \multicolumn{2}{|c|}{ H\% } & \multicolumn{2}{|c|}{ S\% } & \multicolumn{2}{|c|}{ N\% } \\
\cline { 3 - 10 } & & Theo.* & Fd.** & Theo. & Fd. & Theo. & Fd. & Thei. & Fd. \\
\hline Sunflower & 73.0 & undefined & 18.38 & undefined & 13.15 & undefined & 13.58 & undefined & 2.38 \\
\hline Cotton seed & 76.0 & undefined & 19.27 & undefined & 3.31 & undefined & 14.63 & undefined & 2.55 \\
\hline
\end{tabular}

From the obtained results it could be noticed that cotton seed fatty acids sulphonamide had higher yields $(76 \%)$ compared with sunflower fatty acids $(73 \%)$. On the other hand the microanalyses data of both sunflower and cotton seed fatty acids sulphonamide confirm the formation of fatty acid sulphonamide nonionic surfactants.

3. Condensation of fatty acids sulphonamide with ethylene oxide in alkaline medium at $170-180^{\circ} \mathrm{C}$ with different intervals time.

The ethoxylated fatty acids sulphonamide are confirmed by microanalysis and the data are given in Table 3. 
TABLE 3. The yield and microanalysis of the prepared ethoxylated fatty acid

\begin{tabular}{|c|c|c|c|c|c|c|c|}
\multicolumn{2}{|c|}{ Sulphonamides. } & \multicolumn{7}{c|}{ Microanalysis } \\
\cline { 3 - 8 } $\begin{array}{c}\text { Ethyoxylated fatty } \\
\text { acid } \\
\text { sulphonamide }\end{array}$ & Yield (\%) & \multicolumn{2}{|c|}{ C\% } & \multicolumn{2}{c|}{ H\% } & \multicolumn{2}{c|}{ S\% } \\
\cline { 3 - 8 } & & Theo. * & Fd.** & Theo. & Fd. & Theo. & Fd. \\
\hline Sunflower & 70.4 & undefined & 38.56 & undefined & 4.22 & undefined & 8.42 \\
\hline Cotton seed & 68.3 & undefined & 49.69 & undefined & 5.42 & undefined & 10.94 \\
\hline
\end{tabular}

The results in Table 3 indicated the reduction of the found sulpher contents in the formed ethoxylated sunflower and cotton seed fatty acid sulphonamides due to the introduction of the ethoxylated moieties in the backbone of the prepared nonionic surfactants. In addition, the yield of the prepared surfactants was $(70.4 \%)$ and $(68.3 \%)$ for sunflower and cotton seed surfactants, respectively.

Evaluation and performance of the prepared nonionic surfactants

The nonionic surfactants prepared by ethoxylation of fatty acid sulphonamides were evaluated for hydrophile-lipophile balance (HLB), surface tension, interfacial tension, wetting and foaming powers, as well as, $\mathrm{pH}$ value.

The evaluation and performance characteristics of the prepared surfactant are shown in Table 4.

TABLE 4. Evaluation and performance of the prepared nonionic ethoxylated

\begin{tabular}{|l|c|c|c|c|c|c|}
\hline \multicolumn{1}{|c|}{$\begin{array}{c}\text { Type of } \\
\text { surfactant }\end{array}$} & HLB & $\mathbf{p H}$ & $\begin{array}{c}\text { Surface } \\
\text { tension } \\
\text { dyne/cm }\end{array}$ & $\begin{array}{c}\text { Interfacial } \\
\text { tension } \\
\text { dyne/cm }\end{array}$ & $\begin{array}{c}\text { Wetting } \\
\text { power } \\
\text { Time., sec. }\end{array}$ & $\begin{array}{c}\text { Foaming } \\
\text { power } \\
\text { vol. ml. }\end{array}$ \\
\hline Sunflower & 12 & 6.4 & 36 & 12.2 & 106 & 84 \\
\hline Cotton seed & 11 & 6.5 & 35 & 12.5 & 115 & 82 \\
\hline
\end{tabular}

From the obtained results, it can be noticed a slight difference between the prepared nonionic ethoxylated surfactants, while interfacial tension of ethoxylated cotton seed oil is slightly more than sunflower oil.

Biodegradability of the prepared nonionic surfactants

We have mentioned previously in our article (part1) ${ }^{(15)}$ that biodegradability is defined as the destruction of chemical compounds by the biological action of living organisms ${ }^{(16)}$.

The data of biodegradability of nonionic surfactants are presented in Table 5

Egypt. J. Chem. 53, No. 4 (2010) 
TABLE 5. Biodegradability of prepared nonionic surfactants .

\begin{tabular}{|l|c|c|c|c|c|c|c|c|}
\hline \multirow{2}{*}{\multicolumn{1}{c|}{ Type of surfactant }} & \multicolumn{7}{|c|}{ Days } \\
\cline { 2 - 10 } & 5 & 8 & 10 & 12 & 14 & 16 & 19 & 21 \\
\hline Sunflower nonionic surfactant & 28 & 34 & 44 & 54 & 61 & 72 & 80 & 82 \\
\hline Cotton seed nonionic surfactant & 27 & 36 & 43 & 52 & 63 & 74 & 81 & 88 \\
\hline
\end{tabular}

From the obtained results it can be noticed that the prepared sunflower and cotton seed nonionic surfactants are compliance and match well with European Union and Egyptian legalization and requirements. The surfactants are able to biodegrade more than $80 \%$ after 21 days.

It is noteworthy to mention that biodegradability of surfactants was studied at dose of $5-25 \%$ which matches well with the international requirements.

\section{References}

1. Groot, W.H., Sulfonation Tehcnology in the Detergent Industry. Kluwar Academic Publishesrs, Netherlands (1991).

2. Maretti, G.F., "Product application of sulph (on) ates as anionic surfactants". Paper presented at Partical Sulphonation Tehcnology Seminar, 18-20 April 1989, The Hague, Netherlands Center for Professional Advancement, Brunswick, New Jersey 08816, USA (1989).

3. Fable, J., "Surfactants in Consumer Products". Springer Verlag Heideberg, Germany (1987)

4. Maretti, G. F. and Adami, I., Sulphation of ethoxylated alcohols in multitube film reactor: Product quality and reaction control for low dioxang content. Paper presented at the $2^{\text {nd }}$ World Surfactant Congress, Paris 24-27 May (1988).

5. Marei, A. and Badawi, A.M., UAR. C.A., 13, 187-197 (1970).

6. Sisido, K. and Yagi, H., Anal. Chem. 20, 677 (1948).

7. Karabinos, J. V., Hazdra, J.J. and Kapella, G.E., Soap and Chem. Spec. 31,4,49 (1955).

8. Griffin, W.C., "Emulsions": Encyclopedia of Chemical Technology, Vol. 8, 117-154, Interscience Publisher, New York, London, Sydney (1965).

9. Alexander, A.F. and Hayter, J.B., "Physical Methods of Chemistry", John Willy and Sons , New York (1971).

10. Schigfner, R., Melliand Textiber, 41, 1275 (1960).

11. Ross , J. and Miles , G.D., Oil Soap , 18-99 (1941).

Egypt. J. Chem. 53, No. 4 (2010) 
12. Jakobi, G. and Lohr, A., "Detergents and Textile Washing", VCH Verlagsgesellschaft, Weinheim, Germany (1987)

13.Verordnung, Reinigungsmitteln, Abbaubarken Abbaubarken anionischer und nichtioncher grenzflachenaktiver Stoffe in Wasch-und Reinigungsmmitteln vom 18. 6 (1980).

14. Englert, R.D., et al., J. Amer. Oil Chem. Soc. 30, 337 (1953).

15. Megahed. M.G., Abd El-Ghaffar, M.A., Shahin, A. and Rabie, A.M., Mucilage wastes as a source for oils: Part I: Preparation of anionic surfactants, Egyptian J. Chemistry (In press), (2010)

16. Swishev, R.D., Arch. Environ. Health, 17, 232 (1986).

(Received $2 / 12 / 2009$;

accepted 30/8/2010)

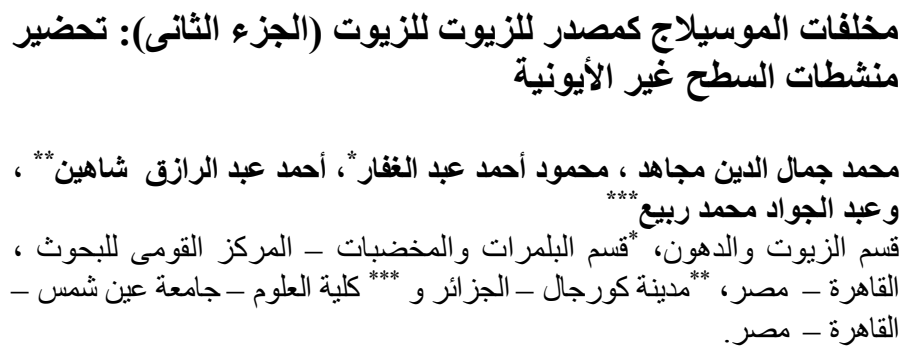

تم تحضير نوعين من منشطات السطح غير الأيونية (nonionic surfactants)

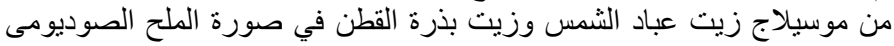

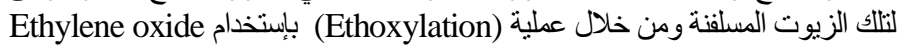

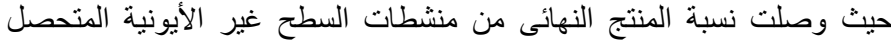

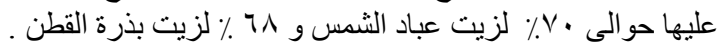

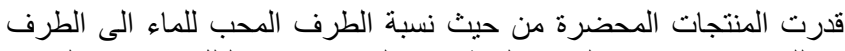

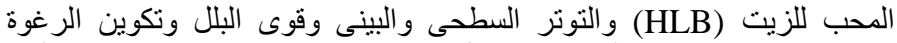

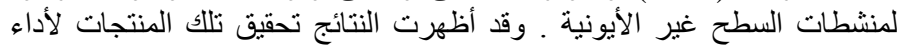

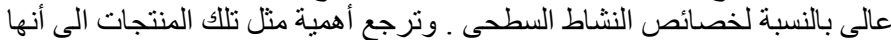

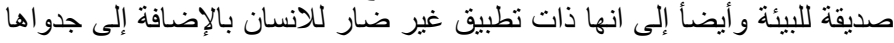
إقتصاديا .

هذا وقد تم دراسة التحلل الحيوى لمنشطات السطح المحضرة حيث أظهرت

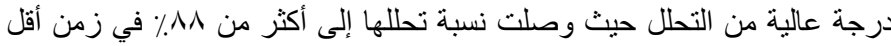

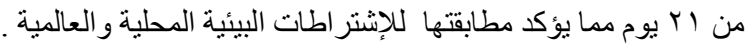

Egypt. J. Chem. 53, No. 4 (2010) 